\title{
correspondence
}

\section{Nuclear pros and cons}

SIR,-As one of the large group of Nobel prize winners having a strong aversion to nuclear energy and its consequence but no "technological background in fields relevant to nuclear technology," I would like to express agreement with a portion of the article by Jan M. Döderlein ${ }^{1}$ entitled "Nuclear power, public interest and the professional," but strong disagreement with much of the rest.

His point about uninformed sponsors of statements was also emphasised in 1973 by the late Eugene Rabinowitch, a person concerning whose judgment and expertise in the area of science and public policy no one could quibble:

"If, at a certain point, their conclusions begin to be affected by extrascientific reasons, they must have sufficient intellectual honesty to state: ' $U p$ to this point, I spoke as a scientist; from here on I will speak also as a politically, ethically or ideologically committed citizen ...'" Still, anyone but the most naive petition signer must understand that sponsors of socio-scientific news releases are, and always will be, selected on the basis of the fact that the general public tends to be influenced by lists of the names of 'dignitaries' of one kind or another (perhaps I should add "so far").

One particular paragraph in $\mathrm{Dr}$ Döderlein's essay seemed to me to be especially noteworthy:

Probably no technological decision in the history of mankind has been the subject of so many detailed studies, so much open discussion and such broad public participation. Amongst it all, some nuclear critics have given prominence to ethical aspects of the nuclear decision. This is justifiable to a certain extent since the application of nuclear power-indeed of any powerraises ethical questions. To carry this view to extremes in the way it is sometimes done, however, represents a vain attempt to set aside fundamental laws of nature and society.

One of the hitherto inevitable consequences of the "laws of nature and society" has been war. Given enough time, conviction and willing hands, and enough spears or rocks, the human species could certainly be doggedly annihilated. However, the existence of nuclear weapons, and the proliferating capacity to make more, makes ultimate mass slaughter not only possible but probable-I know of no technical fixes for human madness and misjudgment. Surely this statement requires no know- ledge of the technology of nuclear power. The ethical and social consequences of the impending plutonium economy are at the very core of the problem $^{2,3}$. We cannot rely, in a world of easy overkill, on "political decisions made in the face of uncertainties". The "uncertainties" associated with nuclear power, both of the electric and military variety, are unfortunately of much larger potential danger than those we have faced in our previous history.

Christian B. Anfinsen

Laboratory of Chemical Biology, National Institute of Arthritis,

Metabolism and Digestive Diseases, National Institutes of Health,

Bethesda, Maryland 20014

1 Döderlein, J. M., Nature, 264, 202 (1976).

2 Scientists' Declaration on Nuclear Power, issued by Union of Concerned Scientists (1208 Massachuset Avenue, Cambridge, Mass.02138; August 1976).
The Plutonium Economy: A Statement of Concern issued by National Council of Churches of Christ in the USA (475 Riverside Drive, New York, New York10027; September 1975).

\section{Evolution and growth}

SiR,-One can agree with Professor Tuzo Wilson (January 20, page 196) that, on the Earth, economic growth cannot continue for ever. But can we plan for stability? It is just not true to say that "undisturbed Nature is stable". Evolution has proceeded as a result of instability. Ecosystems approach stability when they are in a steady state, but even in the steady state phase they are not in fact stable, but oscillating between quantifiable limits. Sudden increases in the size of both populations and of the area they occupy are characteristics of species in an active state of evolution; these are phases of multiplication during which selection pressure is reduced. They alternate with phases of division, in which population size and area of colonisation shrink, and during which selection pressure is increased. As a result, the phyletic line splits, isolation occurs, and new species may arise. Perhaps humanity will be moving into such a phase in the immediate future-but not necessarily so. For evolution in Man is not only controlled by biological processes. Civilisations evolve as a result of psychosocial controls. Under such conditions natural selection no longer operates within a gene-pool, but within an "idea-pool" and it is competition between ideas that leads to evolutionary progress.

Wilson may well be right when he claims that it is the exploitation of energy that has resulted in the sudden increase in the size of the human population. Certainly we can argue that traditional energy supplies must become scarcer in the future. But psycho-social evolution does not necessarily proceed in phase with biological evolution. If our technological advance continues, it may well solve the energy problem. However, it must do more than that if there is to be any further growth of population. We must also solve the problem of living space and the problem of material resources.

On the Earth there is a limit to growth imposed by the fact that both living space and resources are finite. No such limits are imposed in outer space. The only possibility of continued growth would seem to depend on space colonisation. G. K. O'Neill's space colonies (Physics Today, September 1974) could in their first generation exploit solar energy and lunar and asteroidal materials. They could overcome all the constraints that prevent growth on Earth.

So maybe the future of Man will lead to a bifurcation. Some of us will go into space and multiply; the rest of us will stay on the Earth, and divide.

P. C. Sylvester-Bradley

Department of Geology,

The University, Leicester, UK

\section{Journal abbreviations}

SIR,--The abbreviation of periodical titles is a chore to authors and editors, and their secretaries. Abbreviations are also a source of confusion to readers, whom one hopes outnumber the authors. The saving in type-setting which is achieved by the use of abbreviations probably does not justify all this effort.

The British Standards Institution has published a word-abbreviation list (BS 4148: Part 2: 1975) but, like the World List of Scientific Periodicals, this does not always provide unique or unambiguous abbreviations. The French Industrie minérale, for example, shares the abbreviation Ind $\min$ with the British Industrial minerals; $J$ math phys stands equally for Journal of mathematical physics or Journal of mathematics and physics.

I suggest that the practice of abbreviating titles should be discontinued, in favour of full and accurate citations.

Yours faithfully,

AdRIAN SmITH

South Library, University of Leeds,

Leeds LS2 9JT, UK 